IZA DP No. 9254

Wage Compression within the Firm

Marco Leonardi

Michele Pellizzari

Domenico Tabasso

August 2015

Forschungsinstitut zur Zukunft der Arbeit Institute for the Study of Labor 


\title{
Wage Compression within the Firm
}

\author{
Marco Leonardi \\ University of Milan \\ and IZA \\ Michele Pellizzari \\ University of Geneva, \\ CEPR and IZA \\ Domenico Tabasso \\ University of Geneva \\ and IZA
}

\section{Discussion Paper No. 9254 \\ August 2015}

\author{
IZA \\ P.O. Box 7240 \\ 53072 Bonn \\ Germany \\ Phone: +49-228-3894-0 \\ Fax: +49-228-3894-180 \\ E-mail: iza@iza.org
}

\begin{abstract}
Any opinions expressed here are those of the author(s) and not those of IZA. Research published in this series may include views on policy, but the institute itself takes no institutional policy positions. The IZA research network is committed to the IZA Guiding Principles of Research Integrity.

The Institute for the Study of Labor (IZA) in Bonn is a local and virtual international research center and a place of communication between science, politics and business. IZA is an independent nonprofit organization supported by Deutsche Post Foundation. The center is associated with the University of Bonn and offers a stimulating research environment through its international network, workshops and conferences, data service, project support, research visits and doctoral program. IZA engages in (i) original and internationally competitive research in all fields of labor economics, (ii) development of policy concepts, and (iii) dissemination of research results and concepts to the interested public.
\end{abstract}

IZA Discussion Papers often represent preliminary work and are circulated to encourage discussion. Citation of such a paper should account for its provisional character. A revised version may be available directly from the author. 
IZA Discussion Paper No. 9254

August 2015

\section{ABSTRACT}

\section{Wage Compression within the Firm*}

We study the distributional effect of a wage indexation mechanism - the Scala Mobile (SM) that heavily compressed the distribution of Italian wages during the 1970s and 1980s. The SM imposed large real wage increases at the bottom of the distribution and was essentially irrelevant for high-wage workers. We document that this mechanism triggered a strong redistribution within the firm. Skilled workers received lower wage adjustments when employed at firms with many unskilled workers and they tended to move towards more skillintensive firms. We rationalize these findings with a simplified model of intra-firm bargaining with on-the- job search.

JEL Classification: J01, J31, J50

Keywords: $\quad$ labor market institutions, wage indexation, inequality, intra-firm bargaining

Corresponding author:

Michele Pellizzari

Institute of Economics and Econometrics

Geneva School of Economics and Management

University of Geneva

40 Bd du Pont d'Arve

$\mathrm{CH}-1211$, Geneva 4

Switzerland

E-mail: michele.pellizzari@unige.ch

\footnotetext{
* We would like to thank David Card, Giacomo De Giorgi, Andrea Ichino, Thomas Lemieux, Marco Manacorda, Enrico Moretti and Giulio Zanella for useful comments and discussions. We are also very grateful to Giuseppe Tattara and Marco Valentini for providing the data and for their insightful comments. Pietro Ichino helped us reconstructing the functioning of the Scala Mobile. We received useful suggestions from seminar participants at Collegio Carlo Alberto and the 2015 fRDB Workshop of Fellows and Affiliates. All errors remain our sole responsibility. Financial support from the Swiss National Science Foundation is gratefully acknowledged (grant n. 100018 152770).
} 


\section{Introduction}

The link between labor market institutions and wage inequality is the focus of a very large literature (David Card, W. Craig Riddell and Thomas Lemieux, 2004; John Di Nardo and David S. Lee, 2004; John Di Nardo, Nicole Fortin and Thomas Lemieux, 1996; David S. Lee, 1999; Marco Manacorda, 2004). Most of the institutions studied in this area, such as minimum wages and unions, directly affect only workers earning salaries in the lower end of the distribution and researchers have mainly focused on estimating their effects on low-wage earners. ${ }^{1}$ In fact, the causal effects of these institutions on the lower part of the distribution have often been identified empirically by assuming the absence of a causal effect on the upper part (Di Nardo, Fortin and Lemieux, 1996; Lee, 1999).

In this paper we study a labor market policy that was also intended to affect only low-wage earners and we show how instead its effects spanned over the entire distribution. We consider an automatic wage indexation mechanism that was implemented in Italy during the 1970s and 1980s. This system - known as the Scala Mobile (henceforth SM) - mandated that the wages of all dependent employees in the country had to increase each quarter by (at least) the same nominal amount in absolute terms computed as the product of the point change in the price index and a fixed parameter.

The resulting SM adjustments were identical for all workers in nominal absolute value but implied large real wage increases for workers at the bottom of the distribution and real wage cuts for workers at the top. ${ }^{2}$ Since it is unrealistic to imagine that such changes reflected changes in productivity, the SM was obviously binding for low-wage workers and not binding for those earning high wages. ${ }^{3}$ In other words, under any reasonable assumption about the evolu-

\footnotetext{
${ }^{1} \mathrm{~A}$ few papers have looked at the spillover effects of the minimum wage on workers who are paid above the minimum (Edward M. Gramlich, 1976; Jean Baldwin Grossman, 1983; Lee, 1999). However, the analysis has been limited to the close neighborhood of the minimum wage. To the best of our knowledge, John Di Nardo, Kevin F Hallock and Jörn-Steffen Pischke (2000) is the only paper investigating the effect of unions on non-unionized high-wage workers.

${ }^{2}$ Obviously, the SM only defined minimum mandatory adjustments and employers and employees could negotiate additional wage rises.

${ }^{3}$ In a period during which the country was growing by almost $4 \%$ per year and undergoing a process of tertiarization, it is very unrealistic to imagine that the productivity of unskilled lowpaid workers, mostly blue collars, increased by a large amount while that of skilled workers decreased. In the course of the paper we often refer interchangeably to low-paid/unskilled and high-paid/skilled workers.
} 
tion of productivity, the counterfactual real wage changes that unskilled workers would have received in the absence of the SM were lower than those mandated by the SM, whereas skilled workers would have obtained larger pay raises than the mandated SM cuts. ${ }^{4}$ From this point of view, the SM is a labor market institution that, similarly to unions and minimum wages, only directly affects the bottom part of the wage distribution.

Above and beyond its direct effects, our analysis shows that the SM also triggered an important process of redistribution within firms. Over the period of application of the SM, skilled workers employed in firms with many low-wage workers saw their salaries grow less rapidly than similar workers employed in firms with fewer unskilled workers. As a consequence, they tended to leave those firms and moved towards employers with relatively more skill-intensive technologies. We also document that the SM forced the least skill-intensive firms out of the market.

To give a preview of the results and an intuitive idea of the effects of the SM, the automatic application of the system implied a yearly increase of about $30 \%$ of the real wages of workers in the bottom decile of the wage distribution and a decline of about $3 \%$ for workers in the top decile. ${ }^{5}$ Clearly, the SM only mandated minimum wage adjustments and did not forbid employers and employees to negotiate further pay rises. Hence, the SM system could be partly or even completely offset via individual (or sectoral or firm-level) bargaining. We find a sizable offsetting effect, i.e. for each percentage point of mandated SM adjustment the bargained wage change was reduced by 0.3 of a percentage point. Eventually, when we look at total wage changes, workers at the bottom of the distribution still enjoyed a very substantial real wage increase while workers at the top of the distribution barely kept their purchasing power.

As a result, the SM had a different incidence across firms: firms with many low-paid workers were forced to grant each year large real wage increases whereas firms with few low-paid workers barely had to worry about the indexation system. We find a negative strong correlation between the overall burden of the SM

\footnotetext{
${ }^{4}$ Assume, for instance, that the counterfactual real wage changes were zero for all workers, a rather conservative assumption. Then, the SM was irrelevant for all those employees for whom it mandated real wage cuts as they were already receiving more than the mandatory SM adjustment (which is a minimum adjustment). On the other hand, the SM was binding when imposing real wage rises as these were higher than the counterfactual (see Section 3).

${ }^{5}$ To avoid compositional issues, we focus on workers continuously employed between 1976 and 1982, (the core years of the SM system).
} 
at the firm level and the average amount of additional negotiated wage changes. ${ }^{6}$ Workers at the top of the wage distribution were induced to move out of firms with heavy SM burdens to join employers with low SM burdens, which could give them larger additional wage increases over the SM adjustments.

To rationalize these findings, we develop a simplified version of a search model with intra-firm bargaining and on-the-job search, building on the work of Lars A. Stole and Jeffrey Zwiebel (1996) and Pierre Cahuc, Fabien PostelVinay and Jean-Marc Robin (2006). The model features heterogeneous workers (skilled and unskilled) who are complementary in production and heterogeneous employers producing with different combinations of skills. While the wages of unskilled workers are assumed to change exogenously (e.g. according to an automatic wage indexation scheme, like the SM), skilled workers negotiate their salaries over the rents induced by search frictions. With a given probability, skilled workers meet new potential employers and engage in a three-player negotiation involving the incumbent and the poaching firm (Cahuc, Postel-Vinay and Robin, 2006; Ariel Rubinstein, 1982). This process generates labor turnover and wage dispersion across and within firms. The implications of the theory are fully in line with our empirical evidence. An exogenous rise of the wage of the unskilled workers reduces the wage of the skilled and this effect is stronger in firms employing many unskilled workers. Job turnover is characterized by movements of skilled workers from the least skill-intensive to the most skillintensive firms. Rising the unskilled wage also forces the the least skill-intensive employers to exit the market.

Our paper contributes to a number of branches of the literature. The role of the SM in the evolution of wage inequality in Italy has already been studied in Manacorda (2004). However, due to the lack of longitudinal data, that paper only analyzes the effect on overall dispersion and does not look at differences across the distribution nor at the within-firm dynamics. Our data cover the universe of all firms and workers in one region of the country and we can then extend the analysis of Manacorda (2004) in three important directions. First, we estimate the effect of the SM at different points of the distribution of wages, showing that it affected also workers at the very top of the earnings distribution. Second, we exploit the fact that in our data we observe all the employees of each

\footnotetext{
${ }^{6}$ We define the SM burden of the firm as the sum of the real SM adjustments for all the firm's employees as a share of the total wage bill.
} 
firm and we document the importance of within-firm negotiations. Third, we look beyond the wage effect of the SM and we also consider workers turnover across firms and firm exit.

We show evidence that intra-firm bargaining is a key mechanism through which the SM affected wages in the upper part of the distribution. This is consistent with the theories presented in Stole and Zwiebel (1996), Pierre Cahuc, Francois Marque and Etienne Wasmer (2008) and Cahuc, Postel-Vinay and Robin (2006). Due to the scarcity of datasets covering the entire workforce of sampled firms, our paper is among the very few providing empirical support to these models. ${ }^{7}$ In a similar spirit, Luigi Guiso, Luigi Pistaferri and Fabiano Schivardi (2005) and Luigi Guiso, Luigi Pistaferri and Fabiano Schivardi (2013) explore the existence of insurance and credit markets within the firm and our results can also be interpreted in this perspective. To the extent that the SM forces the firm to pay unskilled workers above their marginal product (and in the presence of adjustment costs), employers "borrow" from their skilled employees by reducing their wage adjustments. ${ }^{8}$

Finally, our results also speak to the vast literature on inequality aversion. Most of the studies in this area make use of laboratory experiments or case studies and document pervasive inequality aversion affecting work morale and job performance (Gary Charness and Peter Kuhn, 2007; Dirk Engelmann and Martin Strobel, 2004; Ernst Fehr and Klaus M. Schmidt, 1999; Alexandre Mas, 2006). Despite recent contributions to this topic (e.g. David Card, Alexandre Mas, Enrico Moretti and Emmanuel Saez (2012); Andrew E. Clark and Claudia Senik (2010); Andrew E. Clark, David Masclet and Marie Claire Villeval (2010)), empirical evidence on the general labor market is still limited, perhaps due to the difficulty in finding exogenous sources of variation in inequality within relevant reference groups. In this paper the SM does provide exogenous variation in the distribution of pay within firms and our results on job turnover seem to be counter to the idea that skilled workers are generally averse to inequality, as they moved away from firms where their wages were getting too close to those of the unskilled.

\footnotetext{
${ }^{7}$ Another bargaining model that might be consistent with our findings is Matthew Rabin (2006), as the SM provides a natural reference point for the negotiation of further wage increases.

${ }^{8}$ The extent to which this mechanism really applies in our setting depends on how one expects this credit to be repaid, an issue that eventually rests on expectations about inflation and about the abolition of the SM (or its modification).
} 
The paper is organized as follows. In Section 2 we describe the data and in Section 3 we present a brief history of the SM and its functioning. In Section 4 we present our results on the effects of the SM on the distribution of wages whereas Section 5 looks at workers turnover. Section 6 develops a theoretical framework for interpreting the empirical results. Section 7 concludes.

\section{The INPS Social Security Archives for the region of Veneto}

The dataset used for this study is derived from the archives of the Italian Social Security Administration (INPS). It contains information on all individuals who have worked as dependent employees for at least one day at a private firm located in the region of Veneto between 1975 and 1995. ${ }^{9}$ Once this condition is met, the entire working history of the employee is reconstructed, importing information also from employment spells outside the region. ${ }^{10}$

The unit of observation is the individual employment relationship and the archive includes information about start and end dates, the total compensation paid in each year, the number of working weeks in the year, the type of contract (part-time vs. full time, temporary vs. permanent), the industrial sector of activity, the geographical location of the establishment, gender, age and citizenship of the worker. Both workers and establishments are individually (but anonymously) identifiable and can be followed over time. For firms we observe the date of founding and, if they ceased their activities within the period of observation, the date at which they did so.

Two important limitations of this dataset are worth mentioning. First, there is no information on workers' education. Second, once a worker disappears from the dataset we cannot say whether she was unemployed, inactive or em-

\footnotetext{
${ }^{9}$ Veneto is one of the largest regions of Italy with around 5 million residents. It is located in the north-east of the country and it borders with Austria on the north and Croatia (and the Adriatic sea) on the east. It used to be one of the poorest regions of the country, with very high emigration rates (mostly to Northern Europe and South America). Starting in the 1960s, it experienced very sustained economic growth and it is now one of the richest areas of Italy, comparable to the north-west (Milan, Turin, Genoa), which has traditionally been the wealthiest part of the country.

${ }^{10}$ The same data have already been used in David Card, Francesco Devicienti and Agata Maida (2014); Federico Cingano and Alfonso Rosolia (2012); Marco Leonardi and Giovanni Pica (2013).
} 
ployed in a sector that is not covered by the data (essentially only government jobs and self-employment). We do observe, however, if she returns to private dependent employment.

The original data cover a long period of time (from 1975 to 2004) but we only focus on the years when the SM system had the strongest effect on wages, namely the period between 1976 -the year before the SM was first introducedand 1982 -the year before the first major revision of the system (see Section 3). Throughout the analysis we drop apprentices and managers who were not subject to the SM system and we trim wages at the top and bottom $1 \%$. We further select only workers who held at least one full-time job in each year between 1976 and 1982. For those holding more than one job per year we only consider the longest spell and we annualize earnings for job spells lasting less than the full calendar year.

Eventually, our sample includes 455,324 workers who were employed in 47,682 different firms in 1976. Table 1 presents some basic descriptive statistics for this sample and compares it with the original universe.

\section{[INSERT TABLE 1]}

Compared to the original universe, our estimation sample is younger and better paid whereas most of the other characteristics remain relatively unchanged. Concerning firms, we clearly select a sample of large firms from the original population. The differences are mainly due to our focus on workers who are continuously employed throughout the period of observation. We thus drop older workers who retire at some point between 1977 and 1982 and those experiencing a period of non-employment, who evidently earn lower wages and are presumably employed at smaller establishments.

Despite this selection, our estimation sample clearly reflects some of the most salient characteristics of the Italian labor market of the 1970s. Employees were young (average age is around 33 years), mostly male (only 24\% were women) and blue collars (only $17.6 \%$ of workers in the sample were white collars). The average gross annual wage in 1976 was around 4,001,904 Italian Liras, the equivalent of 18,217 Euros at 2014 prices. This includes the

worker's base salary and additional monetary payments for extra-hours, payfor-performance, sickness and maternity benefits. In kind benefits are excluded. Average wages are higher for males than for females (around Euros 19,000 for 
males and slightly more than 15,000 for women) and for white collars than blue collars (almost 24,000 Euros against 17,000 Euros). Around 64\% of these workers never changed employer during the interval of time under analysis. The bottom panel of Table 1 presents descriptive statistics for the firm sample. The distribution of firm size is very skewed, with a few very large firms and a large number of small and very small ones. The average number of full-time equivalent employees is equal to almost 15 workers and the median is 4.2 .

Figure 1 compares the evolution of overall wage inequality (measured by the standard deviation of $\log$ wages) in Veneto and in the entire Italy. ${ }^{11}$ The vertical bars indicate crucial times in the history of the SM system, which was first introduced in 1977, then reformed to limit its equalizing effects in 1983 and 1986 and finally abandoned in 1992 (see Section 3).

\section{[INSERT FIGURE 1]}

Overall, the evolution of wage inequality in Veneto resembles closely what is observed for the rest of the country. Figure 1 shows that inequality in Italy declined substantially from the late 1970s and until the mid-1980s. Then, it rose rapidly until the late 1990s and flattened out, and possibly reversed, in the first half of the 2000s. ${ }^{12}$ As formally documented in Manacorda (2004), this pattern suggests that the SM played an important role in artificially compressing the distribution of wages and that its gradual abolition led to larger and larger dispersion.

\section{A brief history of the Italian Scala Mobile}

Wage indexation mechanisms started to be adopted in Italy already after WWII, with large differences across sectors, geographical areas, qualifications and even gender. There was, in fact, no national legislation on the issue and the entire matter was delegated to bilateral negotiations between unions and employers.

\footnotetext{
${ }^{11}$ The data for the entire country are derived from the historical archives of the Bank of Italy Survey of Household Incomes and Wealth (SHIW).

${ }^{12}$ This can be compared with a more continuous rise in wage inequality over the same period experienced in the US and the UK. In the US, in particular, while the ratio between the wages in the 50th percentile and those the in the 10th percentile ratio stabilized in the 1990s, the 90/50 ratio shows an uninterrupted growth even in the most recent data (David H. Autor, Lawrence F. Katz and Melissa S. Kearney, 2006).
} 
Only in 1977 a national law imposed the same indexation system to all dependent employees, the so-called Scala Mobile (SM). ${ }^{13}$ The only exceptions were managers, who always maintained their pre-1977 scheme, and employees in the public sector, for whom the common system was introduced a little later, in July 1978.

The SM mandated that each quarter the wages of all dependent employees in the country increased by the same nominal absolute amount computed as a the product of the point change in the price index and a fixed parameter, named the contingenza point. Since the absolute SM adjustment was identical for all workers, it obviously implied a much larger percentage change for workers earning low wages than for those earning high wages. Hence, the system had a powerful equalizing effect, especially given the exceptionally high inflation rates experienced by the country during this period (21.2\% in 1980). In fact, one of the main problems with the SM was that it was itself generating inflation, as firms transferred the mandated wage rises into higher prices.

The system was reformed a first time in 1983. The base period of the price index was changed and the new contingenza point was set at a lower level than the one that would have been obtained by mechanically updating the old value according to the new price index. All in all, the 1983 reform reduced the generosity of the SM by about 15\% (Christopher L. Erikson and Andrea Ichino, 1995).

In the following years the SM became the target of fierce opposition, especially from skilled workers who perceived its strong equalizing effect as unfair. ${ }^{14}$ Eventually the indexation mechanism was further and more substantially modified in 1986. First, the SM adjustments started to be paid out every 6 rather than 3 months (in April and October). Second and most important, the fixed contingenza point was abandoned and wage adjustments were made almost entirely proportional to inflation. Specifically, the new SM system set percentage wage rises equal to inflation up to a (sector and occupation-specific) contractual minimum and equal to one-fourth of inflation for the part exceeding the minimum. Eventually the entire system of wage bargaining was reformed in 1992 and the SM was abandoned: the last automatic wage increase was paid in

\footnotetext{
${ }^{13}$ The Italian term Scala Mobile means escalator and is evocative of the automatic wage adjustments implied by the indexation mechanism.

${ }^{14}$ Frustration among white collars culminated in the famous "march of the forty thousand", one of the few examples of mass strikes by white collars.
} 
October 1991.

In summary the equalizing power of the SM was strongest between 1977 and 1982, much milder between 1983 and 1985, and it essentially disappeared after 1986. Excluding this last period (post-1986), Figure 2 presents a simple exercise that helps quantifying the potential effect of the SM on the distribution of wages before and after the reform of $1983 .^{15}$

\section{[INSERT FIGURE 2]}

The left panel of the figure shows the actual distribution of annual wages in 1976 and simulates the distribution that would have resulted two years later from the automatic application of the SM (at constant prices). In other words, the hypothetical distribution in 1978 is constructed by adding the SM payments to each individual wage in 1976 year by year and reporting all values at 1976 prices. Both distributions are rescaled to have mean zero so that they only differ by their degrees of dispersion. The right panel of the figure illustrates the same exercise for the period 1983-1985, after the 1983 reform of the system which substantially reduced the equalizing power of the SM. This is evident from the figure. While the application of the SM pre-reform system reduces the standard deviation by 24 percentage points in two years, the post-reform SM system reduces it only by 17 percentage points over the same time span.

In the rest of our analysis we restrict our attention to the initial period of application of the SM, namely the years between 1976 and 1982, when the equalizing power of the system was strongest. Table 2 provides the exact details of the functioning of the indexation mechanism during this period. SM adjustments were paid at quarterly frequency, in January, April, July and October. For each quarter between April 1977 (the first adjustment) and October 1982 (the last adjustment before the 1983 reform), the table reports the level and the point change of the price index, the contingenza point and the actual mandated SM adjustment. This is computed as the product of column [2] and column [3] in the table, namely as the product of the (rounded) point change in the price index and the contingenza point. For example, in April 1977 the price index was 149 and it had increases by 6 points (rounded) since the previous

\footnotetext{
${ }^{15}$ Performing the same calculations for the period after 1986 is more complicated because it requires knowledge of the entire set of contractual minimum wages, which are not available in our data and are very difficult to reconstruct. Card, Devicienti and Maida (2014) were able to reconstruct the minima but only for the period after 1995 and only for some industries.
} 
quarter. Then, all private dependent employees in the country had their wages risen by $6 \times 2,389=14,334$ Liras. The same procedure was replicated at each quarter as described in Table 2 .

\section{[INSERT TABLE 2]}

It is perhaps useful at this point to make a specific example to further clarify the role of the SM for workers at different points of the distribution of wages. The 6 percentage points increase of the price index between January and April 1977 implies a percentage change of approximately 4\%. ${ }^{16}$ The SM adjustment of 14,334 Liras corresponds to a percentage increase of $4 \%$ (i.e. exactly in line with inflation) for a monthly wage of around 360,000 Liras (approximately 1,380 Euros at 2014 prices). Therefore the SM adjustment implied a real wage increase for anyone earning less than this amount and a real wage cut for anyone earning more.

Consider for example a skilled white collar earning a monthly salary of 560,000 Liras in 1977 (around the 90th percentile of the distribution) and imagine that in the absence of the SM her wage would have been updated to keep up with inflation (a conservative counterfactual). This implies an increase of 22,400 Liras, i.e. 4\% between January and April 1977. The SM required her employer to pay her at least a wage increase of 14,334 Liras but it obviously did not forbid a larger rise of 22,400 . In this sense the SM was irrelevant for such a worker because it is lower than any realistic counterfactual. The 14,339 Liras correspond to a real wage cut of about $1.3 \%$ so, for the SM to be binding in this case, one needs to assume that, absent it, the wage would have been cut by more than $1.3 \%$ in real terms on a quarterly basis. This seems highly unrealistic in a period in which the country overall was growing at around $4 \%$ per year and undergoing a process of tertiarization suggesting that most of the growth came from skilled white collars in the service sector. In fact, it seems much more reasonable to assume that the counterfactual wage changes for skilled workers would have been positive in real terms.

Obviously, the system was binding for unskilled workers earning low wages. Consider, for example, someone at the 10th percentile of the distribution in 1977 earning 235,000 Liras per month. If we still assume the conservative counterfactual scenario in which, absent the SM, real wages would have been kept

\footnotetext{
${ }^{16}$ Notice that this is the quarterly increase. Yearly inflation was $18.1 \%$ in 1977.
} 
constant, she should have received a nominal rise of 9,400 Liras in April 1977 (i.e. $4 \%$ of 235,000). Therefore, the SM-imposed minimum increase of 14,334 Liras corresponds to a real rise of about $2 \%$. In this case the system clearly impeded the implementation of the counterfactual and employers needed to adjust upwards their wage policies.

\section{Wage changes under the Scala Mobile}

A proper understanding of the effect of the SM on the distribution of wages requires taking into account not only the mandatory adjustments imposed by the system but also the additional wage changes that could be negotiated between employers and employees.

The Italian bargaining framework of the time offered ample scope for negotiations above and beyond the SM. Salary levels were negotiated collectively by employers and unions representatives at the national level and by sectors. These collective agreements were legally binding for all workers and firms in the economy regardless of their affiliation to the unions or the employers' federation (the so-called erga omnes clause). Further wage increases could be negotiated at the firm level either individually or collectively for all workers or groups of workers (e.g. blue collars and white collars). All these different levels of bargaining took place at irregular intervals over the period 1977-1982, with national wage agreements being signed at different times for different sectors and with negotiations at the firm level occurring erratically and often separately for different categories of workers.

To avoid complications due to this heterogeneity in the timing of bargaining, we focus on wage changes over the entire period. More specifically, we consider the wages in 1976, the last year before the introduction of the SM, and we compare them with those in 1982, the last year before the first important reform of the indexation mechanism. ${ }^{17}$

To understand the functioning of the SM, it is useful to start from the simple nominal wage change between 1976 and 1982 and to rewrite it as the sum of the SM adjustment and a residual change capturing the combined outcome of

\footnotetext{
${ }^{17}$ Manacorda (2004) follows the same approach but considers the period 1977-1985. Results for the period 1983-1985 are similar to those presented in this section but smaller in magnitude. They are available from the authors upon request.
} 
all the other negotiations:

$$
\Delta W_{i}=s \Delta P+\Delta W_{i}^{N}
$$

where $\Delta W_{i}$ is the simple difference between the nominal wages of worker $i$ in 1982 and in 1976, $s$ is the nominal contingenza point, $\Delta P$ is the point difference in the price index and $\Delta W_{i}^{N}$ is the residual negotiated change. ${ }^{18}$ Equation 1 clearly shows that the SM adjustment was the same for all workers and that any heterogeneity in the overall wage change could only come from the negotiated part.

From equation 1 it is easy to compute nominal percentage wage changes by dividing both sides by the wage in $1976\left(W_{i(76)}\right)$ :

$$
\frac{\Delta W_{i}}{W_{i(76)}}=\frac{s \Delta P}{W_{i(76)}}+\frac{\Delta W_{i}^{N}}{W_{i(76)}}
$$

For notational simplicity we will label $\Delta w_{i}=\frac{\Delta W_{i}}{W_{i(76)}}$ the total wage change, $\Delta w_{i}^{s}=$ $\frac{s \Delta P}{W_{i(76)}}$ the SM adjustment and $\Delta w_{i}^{n}=\frac{\Delta W_{i}^{N}}{W_{i(76)}}$ the negotiated change. Equation 2 shows that, while the nominal absolute SM adjustment was identical for all workers, it implied different percentage changes depending on the level of the initial wage. When compared to inflation (which between 1976 and 1982 totaled $157 \%$ ) the SM granted positive and often substantial real wage increases at the bottom of the distribution and real wage cuts at the top. This is clearly evident in Figure 3 which plots the averages of $\Delta w_{i}, \Delta w_{i}^{s}$ and $\Delta w_{i}^{n}$ for each percentile of the distribution of $W_{i(76)}$. The horizontal line indicates the rate of inflation between 1976 and $1982(+157 \%) .{ }^{19}$

\section{[INSERT FIGURE 3 HERE]}

The red dotted line represents the percentage wage changes induced by the sole application of the $\mathrm{SM}\left(\Delta w_{i}^{S}\right)$. It shows that the system granted real wage increases up to the 12th percentile while for all wages above that level the SM

\footnotetext{
${ }^{18}$ The computation of the SM change over the entire period is slightly more complicated than the simple product $s \Delta P$ as one needs to consider that the adjustments were computed quarterly. However, the nominal SM adjustment remains the same for all workers regardless of whether it is computed quarterly, annually or over several years as we do in this section.

${ }^{19}$ Only workers who never changed firm between 1976 and 1982 are used for the figure.
} 
alone implied real wage cuts. At the very bottom of the distribution the SM adjustments were very substantial, of the order of $400 \%$ in nominal terms and 400$157=243 \%$ in real terms for the first decile. Symmetrically, the SM mandated substantial real wage cuts at the top: the cumulative nominal percent increase in the top decile was $20 \%$ over the entire period compared to a cumulative inflation rate of $157 \%$.

Figure 3 also shows that negotiated wage changes (the dashed line in the picture) correlate negatively with the SM, suggesting that they were presumably used to offset, at least partially, the compression induced by the SM. Such negative correlation is particularly evident at the bottom of the distribution where very large SM increases were largely compensated by negative negotiated changes; at the top of the distribution negotiated wage changes only partially recouped the negative changes imposed by the SM.

Eventually, during the period 1976-1982, real wages increased overall by about $60 \%$ on average but by almost $200 \%$ in the bottom decile and by only $10 \%$ in the top decile (and virtually zero at the very top of the distribution). This can be seen by looking at the difference between the solid green line (which represents total nominal wage changes and is the sum of the other two lines) and the horizontal line of inflation.

The negative correlation between SM adjustments and negotiated changes observed in Figure 3 suggests that worker-firm bargaining was heavily influenced by the system. The other obvious factor that must have entered the negotiations was the evolution of productivity, which is unfortunately unobserved in our data. To assess more precisely the influence of the SM, we then express the negotiated changes as a function of both the SM adjustment $\Delta w_{i}^{s}$ and a number of other factors that should capture changes in productivity and any other confounding factor:

$$
\Delta w_{i}^{n}=\alpha_{0}+\alpha_{1} \Delta w_{i}^{s}+\beta X_{i}+\varepsilon_{i}
$$

where $X_{i}$ includes a gender dummy, a quadratic function of age, fixed effects for the firm in which $i$ is employed in 1976 and a quadratic function of the percentile of $W_{i(76)}$ to allow for a differential dynamics of productivity at different points of the distribution. If negotiated changes were used to offset the SM one should expect the estimated $\alpha_{1}$ to be negative: $\alpha_{1}=-1$ would imply complete 
offsetting and $\alpha_{1}=0$ would indicate no offsetting.

The specification in equation 3 is equivalent to Manacorda (2004) with the important difference that we have a large sample of longitudinal individual data whereas Manacorda (2004) only had access to repeated cross-sections and was forced to aggregate the data by percentile-gender cells. In that setting the identification assumption was that productivity (or more generally the latent counterfactual wage change) would have been the same for men and women located at the same point of the distribution of wages. We make the similar but much weaker assumption that productivity evolves between 1976 and 1982 in the same way for workers who are employed in the same firm in 1976, who are paid similarly in 1976 and who are in the same age-gender group. ${ }^{20}$

\section{[INSERT TABLE 3 HERE]}

The estimate of $\alpha_{1}$ from equation 3 is reported in the first column of Table 3 and is equal to -0.318 . This result indicates that, for every percentage point increase in wages commanded by the SM, negotiated wage changes were lowered by about 0.3 percentage points. Considering that for the average worker $\Delta w_{i}^{s}$ was equal to approximately $100 \%$ between 1976 and 1982, our estimate implies that negotiated changes were reduced by the SM by around 32 percentage points, an effect that is substantially larger than that of gender (23 p.p., coefficient not shown in the table).

In the second column of Table 3 we then interact $\Delta w_{i}^{s}$ with an indicator for whether the worker stayed in the same firm for the entire period 1976-1982. We find that the cut in the negotiated changes was on average lower for the job stayers by about 10 percentage points, which was presumably the reason why they eventually stayed with their employers. ${ }^{21}$ In column 3 of Table 3 we further interact $\Delta w_{i}^{s}$ with dummy indicators for one's position in the 1976 distribution of wages. Results indicate that, in line with what we observed in Figure 3, the effect of the SM on the negotiated margin was stronger in the bottom deciles and then declines monotonically from the third decile onward. Importantly, a sizable offsetting effect remains also in the top deciles of the distribution.

\footnotetext{
${ }^{20}$ The dependent variable in equation 3 is the negotiated wage change $\Delta w_{i}^{n}$ instead of the total change $\Delta w_{i}$, as in Manacorda (2004). Hence, our estimate of $\alpha_{1}$ for the entire population (the -0.318 in the first column of Table 3 ) must be compared with the estimate reported in Manacorda (2004) minus one (the 0.653 in the first column of Table 3 ). The two are remarkably similar.

${ }^{21}$ Recall that our sample is restricted to workers who are always employed throughout the period, hence the job changers are exclusively job-to-job changers.
} 
The persistence of the offsetting until the very top of the distribution is one of the most notable findings of this paper because, in principle, the SM should have had no direct effect on those workers. Figure 3 showed that the mandated SM adjustments cumulated over the entire period totaled to approximately $20 \%$ in the top decile of the distribution, which, compared to a rate of inflation of $157 \%$, implied huge real wage cuts. If one makes the rather conservative assumption that, absent the SM, the wages of workers in the top decile would have simply stayed constant in real terms, one should expect no effect whatsoever on these high-wage workers. In fact, their counterfactual wage adjustments would have been equal to inflation (i.e. 157\%) and would have been perfectly consistent with the legal requirements of the SM, which simply stipulated wage changes of at least $20 \%$. Of course, pay rises larger than the SM were not forbidden. Hence, the significant coefficient of $\Delta w_{i}^{s}$ for the upper deciles of the distribution in Table 3 can only be rationalized with some sort of indirect spillover effect. ${ }^{22}$

\section{[INSERT FIGURE 4 HERE]}

Figure 4 reports the estimates of the third column of Table 3 separately for job stayers and job changers (for convenience these results are shown only graphically). The figure shows that the offsetting effect of the SM was stronger for job stayers up until the 7th decile whereas for the most skilled workers in the top $20 \%$ of the distribution the reverse occurred. Beyond the specific patterns of these estimates along the distribution, it is important to notice that the effects were significantly different for the two groups, suggesting that the adjustment to the SM took place both on prices and on quantities, namely on both wages and workers turnover. We analyze the effects of the SM on workers turnover more accurately in Section 5.

\subsection{The Scala Mobile within the firm}

In order to understand the nature of the spillover effects detected in Table 3, we want to investigate the extent to which individual negotiated wage changes were affected by the SM adjustments paid to co-workers within the same firm. To this end, we take the firm's employment composition in 1976 and we compute the

\footnotetext{
${ }^{22}$ Manacorda (2004) produces similar estimates (by quintiles) but, due to more stringent data limitations, his results are never significant at the usual statistical levels and are only reported in a footnote (see footnote 6 on page 603).
} 
sum of all the real SM adjustments that were due by the employer in 1977 . We then express this sum as a fraction of the total wage bill in 1976:

$$
\text { SMburden }_{i j}=\frac{\sum_{(h \neq i) \in j}\left[\frac{W_{h(76)}+s \Delta P_{76-77}}{P_{77} / P_{76}}-W_{h(76)}\right]}{\sum_{(h \neq i) \in j} W_{h(76)}}
$$

where $j$ is the firm where worker $i$ was employed in 1976 and $\frac{W_{h(76)}+s \Delta P_{76-77}}{P_{77} / P_{76}}$ is the wage (at 1976 prices) that a generic co-worker $h$ would have received in 1977 if only the compulsory SM adjustment were granted. So, the numerator of equation 4 is the sum at the firm level of all the absolute real SM adjustments due by the firm in 1977 to its 1976 employees (excluding $i$ ). The denominator is simply the wage bill of the firm in 1976 (excluding $i$ ).

SMburden $_{i j}$ is a summary indicator of the burden imposed on the firm by the SM, holding the employment composition fixed in 1976, prior to the introduction of the system. ${ }^{23}$ Firms with lots of low-paid workers would have to pay large shares of their wage bill in SM adjustments whereas SMburden ${ }_{i j}$ would be negative for firms with only high-wage employees, as the SM would only require them to pay negative real wage adjustments.

\section{[INSERT TABLE 4 HERE]}

Table 4 reports some descriptive statistics on the SM burden at the firm level. On average $S_{M b u r d e n}$ is equal to about -0.011 , as positive real SM wage changes are only due to workers in the bottom $12 \%$ of the wage distribution. However, the burden imposed by the system varied widely across firms. Firms in the top $20 \%$ of the distribution of $S M b u r d e n_{i j}$ pay over $5 \%$ of their wage bill in $\mathrm{SM}$ adjustments and this percentage reaches $14 \%$ in the top percentile. Of course, SMburden $_{i j}$ correlates very strongly with the skill composition of employment at the firm. For example, firms in the top $20 \%$ of the distribution of the burden employ approximately $10 \%$ of white collars and over $76 \%$ of workers with wages in the bottom quintile. Conversely, firms with burden in the bottom $20 \%$ employ $30 \%$ of white collars and $50 \%$ of workers in the top quintile of the wage distribution.

\footnotetext{
${ }^{23}$ In equation 4 we consider only the SM adjustments due in 1977 to avoid making unnecessary assumptions about agents' expectations about future price levels.
} 
We then augment the specification of equation 3 with $\operatorname{SMburden}_{i j} .{ }^{24}$

$$
\Delta w_{i}^{n}=\alpha_{0}+\alpha_{1} \Delta w_{i}^{s}+\alpha_{2} \text { SMburden }_{i j}+\beta X_{i}+\varepsilon_{i}
$$

In all specifications we standardize the variable $S_{M}$ burden $_{i j}$ so that the coefficients can be readily interpreted in terms of standard deviation changes. Results are shown in Table 5.

\section{[INSERT TABLE 5 HERE]}

Conditional on one's individual SM adjustment $\left(\Delta w_{i}^{S}\right)$ and on one's position in the original wage distribution, negotiated wage changes are lower in firms that are more heavily constrained by the system. The magnitude of the effect is large: one standard deviation difference in $S_{M b u r d e n}{ }_{i j}$ is associated to negotiated wage changes that are 7.5 percentage points lower. In column 2 of Table 5 we interact the firm's SM burden with a dummy for job stayers and we find that the spillover effect is almost exclusively relevant for this group (-10.7 p.p.). For job changers the coefficient estimated on $S_{M b u r d e n_{i j}}$ is only -0.9 p.p., i.e. 12 times smaller.

In column 3 we interact $S M b u r d e n_{i j}$ with the deciles of the distribution of individual wages in 1976. The spillover is clearly stronger for low wage workers but interestingly it persists and remains sizable up to the very top. It is only for the $10 \%$ most paid workers that the effect changes sign, perhaps due to employers attempting to retain their most skilled employees. In the next section we will analyze workers mobility and in the model of Section 6 we will formalize how low skill-intensive firms may renegotiate wages in an attempt to retain skilled worker.

\section{[INSERT FIGURE 5 HERE]}

To further investigate the differences between stayers and movers, Figure 5 shows the estimates of the third column of Table 5 separately for stayers and movers. ${ }^{25}$ Results show that the negative effect on negotiated wages of a high

\footnotetext{
${ }^{24}$ Compared to the specification in equation 3 we also change the set of controls, namely by excluding the firm fixed effects as they would be very collinear to our main regressor of interest SMburden $_{i j}$. The only variation in $S_{M b u r d e n_{i j}}$ within firm is generated by the exclusion of the wage of worker $i$ from the calculation in equation 4.

${ }^{25}$ The estimates come from the same specification of equation 5 where both $\Delta w_{i}^{s}$ and SMburden $_{i j}$ are interacted with the ten decile dummies.
} 
SM burden is always stronger for the stayers and that it becomes less and less pervasive towards the upper part of the distribution until it essentially disappears at the very top. In other words, the estimates in Figure 5 suggest that the firms that were more heavily affected by the SM tended to negotiate smaller discretionary wage adjustments to stayers at the bottom of the wage distribution. However, they also apparently tried to limit the negative spillover for the most skilled workers granting them higher percentage negotiated wage changes. The difference between job stayers and job movers, which tends to disappear for highly paid workers, suggests that a plausible reason for paying higher negotiated wage changes to workers at the top of the distribution is their higher probability of changing jobs. In the next section we investigate the effect of the SM on worker turnover more in details.

\section{Workers turnover and firm exit under the Scala Mobile}

In Section 4 we have analyzed the effect of the SM on the distribution of wages. We have documented distinctive different results for job stayers and job changers, suggesting that the economy adjusted to the indexation mechanism both along the price and the quantity dimension. In this section we focus specifically on workers turnover. We still concentrate on the same balanced sample of Section 4 and we estimate a model very similar to equation 5 but with a dummy indicator for whether the worker changed employer over the period of analysis.

\section{[INSERT TABLE 6 HERE]}

Results are reported in Table 6 and show that, holding constant the individual SM payment $\left(\Delta w_{i}^{S}\right)$ and one's position in the wage distribution (in 1976), a worker is still significantly more likely to change employer when the firm is more heavily constrained by the SM, namely when $S_{M b u r d e n}{ }_{i j}$ is higher. The estimated effect is of notable magnitude. A one standard deviation increase in the firm SM burden increases the probability of changing job by approximately 3.1 percentage points over an average of $36 \%$.

In column 2 of Table 6 we investigate how this effect varies along the distribution of wages by interacting $S M b u r d e n_{i j}$ with decile dummies. The estimates 
indicate that the effect increases steeply moving up from the bottom deciles to the top ones. In fact, workers in the bottom $10 \%$ of the distribution are unlikely to move from firms with large burdens. Presumably this is because they already receive very substantial real wage increases from the SM and no employers would be prepared to negotiate further pay raises. However, as the wage decile increases workers become more and more prone to leave firms with high SM burdens. This pattern is consistent with the results in Table 5 and Figure 5 which show that skilled workers who stayed with their employers could be subject to substantial negative spillover effects from the SM.

\section{[INSERT FIGURE 6 HERE]}

Figure 6 investigates the characteristics of the destination firms towards which job changers move. To construct this figure (left panel) we consider only the job changers and for each of them we compute the difference in the SM burden of their firms in 1982 and in 1976. We apply a simple partitioned regression procedure. First, we regress such difference on all our usual covariates, namely a quadratic function of age, a gender dummy and fixed effects for the 1976 firms, and we take the residuals. Then we also regress the wage in 1976 on the same set of controls and take the residuals. Finally, for each percentile of the residuals of the wage regression we plot on the graph the average residual of the first regression. The negative correlation between the difference of the SM burden (the SM burden of the destination firm minus that of the original firm) and the initial wage percentile of the worker in 1976 indicates that the better paid workers were moving away from firms with high SM burden towards firms with low SM burden.

The right panel of Figure 6 replicates the same exercise replacing $S M b u r d e n_{i j}$ with the share of white collars in the firm. The vertical axis of the right panel shows the difference between the incidence of white collars in the receiving and origin firms. The results are consistent with those in the left panel of the figure: highly paid workers in low skill-intensive firms tend to move to more skill-intensive firms. ${ }^{26}$

With high-paid workers leaving and ever increasing SM burdens, low skillintensive firms were more likely to go out of business. Table 7 uses firm-level

\footnotetext{
${ }^{26}$ The SM burden and the share of white collars of the firm are inversely correlated, as shown in Table 4
} 
data to look at the pattern of firm exit. ${ }^{27}$ The dependent variable is a dummy that takes the value of one if the firm closes down between 1977 and 1982 . A simple linear probability model indicates that the likelihood of exiting the market decreases with skill intensity and increases with the SM burden (both measured in 1976): one standard deviation increase in the SM burden leads to a 1.1 p.p. increase in the exit probability (over an average of around 28\%).

\section{[INSERT TABLE 7 HERE]}

To sum up, our empirical results can be summarized in the following way. As the SM system mandated higher nominal wage adjustments (i) negotiated wage changes were lowered, also for high-paid workers, (ii) who were particularly penalized when employed in low skill-intensive firms and (iii) tended to leave such firms to move towards more skill-intensive ones; (iv) low skillintensive firms were more prone to exit the market.

\section{A model of within-firm bargaining and on-the- job search}

In this section we present a simplified matching model that helps rationalizing the empirical evidence documented in the previous sections. Consider an economy with two types of workers - the skilled $(H)$ and the unskilled $(L)$ - and heterogeneous firms producing using different combinations of workers.

For tractability we assume the following production function:

$$
y_{\rho}=\left(x_{H}+\rho x_{L}\right) \min (H, L / \rho) \quad \text { with } \rho \geq 1
$$

where $x_{H}$ and $x_{L}$ are the productivities (or the contributions to output) of skilled and unskilled workers respectively and $\rho$ is the parameter of firm heterogeneity. ${ }^{28}$ Equation 6 defines a class of Leontief production functions that can be easily interpreted as team work. For example, a firm with $\rho=1$ produces using

\footnotetext{
${ }^{27}$ Notice that, while for all other tables and figures in the paper we always use the estimation sample described in Table 1, here we select the sample of firms where the workers in our estimation sample are observed in 1976 and we look at whether these firms are still operating in 1982.

${ }^{28}$ For simplicity, we normalize $x_{L}$ to equal 1.
} 
teams composed by one skilled and one unskilled worker; therefore, if it employs one unskilled and two skilled workers, only one team is productive and one of the unskilled workers is not contributing to output. A firm with $\rho=2$ produces with teams of one skilled worker and two unskilled. Hence, the parameter $\rho$ can be interpreted as the inverse of skill intensity. One skilled worker is always needed to operate the team but there are many types of firms, producing with few or many unskilled workers per team. We assume that $\rho$ is distributed according to a generic $\operatorname{cdf} P(\cdot)$ over the support $[1,+\infty] .{ }^{29}$

The production process in equation 6 captures the essence of skill complementarities while at the same time maintaining individual productivities independent of one another (conditional on production taking place) and avoiding the complications due to the differences between marginal and infra-marginal workers which are unnecessary for our purposes (Cahuc, Marque and Wasmer, 2008; Stole and Zwiebel, 1996).

We start from an initial, exogenously given, allocation of workers to firms assuming no unemployment nor inactivity. This is admittedly a very restrictive assumption but it is coherent with our empirical analysis which focuses exclusively on a balanced panel of individuals who are continuously employed, possibly at different firms, over the period 1976-1982. We further assume that frictions prevent firms from changing their production technologies and workers will have the opportunity to meet a new potential employer only with some probability $\lambda$ smaller than 1 .

The wages of the unskilled workers are set exogenously at a fixed level $\bar{w}$ for all firms. We assume that such pay level changes only in relation to changes in the minimum wage or new rounds of unions negotiations or, as it is relevant for our application, according to a statutory indexation system like the SM. With no variation in wages across firms, there is no reason for unskilled workers to change employer and we will assume that they never do. ${ }^{30}$

The wages of skilled workers are negotiated according to a strategic bargaining process similar to that in Cahuc, Postel-Vinay and Robin (2006). Let us first consider workers who do not have the opportunity to change employer. Their

\footnotetext{
${ }^{29}$ Notice that $\rho$ does not necessarily define firm size, as each firm can operate multiple teams. We maintain the assumption that all the teams of the same firm must adopt the same technology.

${ }^{30}$ Unskilled workers may have an incentive to move from less- to more skill-intensive firms if they anticipate that the first have a higher probability of exiting the market but we abstract from this effect.
} 
wages are set by maximizing the weighted product of the partners' surpluses:

$$
w_{0}(\rho)=\max _{w}(w-u)^{\gamma}\left(y_{\rho}-\rho \bar{w}-w\right)^{1-\gamma}
$$

where $w_{0}(\rho)$ is the wage paid to a $\mathrm{H}$-worker at a $\rho$-firm, $\gamma$ is the bargaining power of the worker and $u$ is the value of unemployment. The surplus of the firm is derived under the assumption that if the negotiation fails and the skilled worker is not hired the entire team is dismissed at no cost and that the value of vacant jobs is zero. ${ }^{31}$ For simplicity we normalize the value of unemployment to zero $(u=0)$ and we derive the following solution to the maximization problem in equation 7 :

$$
w_{0}(\rho)=\gamma\left[x_{H}-\rho(\bar{w}-1)\right]
$$

Equation 8 clearly shows the nature of the spillover effect between the wages of the unskilled and the skilled workers. As the exogenous salary of the unskilled increases, for example because of a mandatory SM adjustment, employers extract more rents from the wages of their skilled employees through individual or firm-level negotiations. The derivative of $w_{0}(\rho)$ with respect to $\rho$ is $-\gamma \rho$ indicating that this effect is stronger in firms employing many unskilled workers (relative to the skilled). This is consistent with our results in Table 5 which show that low skill-intensive firms with high SM burdens pay lower wages.

If $\bar{w}$ is larger than 1 , which corresponds to the productivity of the unskilled $\left(x_{L}\right)$, then $w_{0}(\rho)$ is decreasing in $\rho$. In other words, if the employer is forced to pay the unskilled above their productivity, then $\mathrm{H}$-workers are better paid in more skill-intensive firms (i.e. with lower $\rho$ ). Under this assumption, $\mathrm{H}$-workers will never want to move to less skill-intensive employers (i.e with higher $\rho$ ), however, they would like to move to more skill-intensive firms (i.e. with lower $\rho$ ) if they have the opportunity to do so.

Assume that skilled workers meet new potential employers with probability $\lambda$. The type of the poaching firm, denoted with $\rho^{\prime}$, is randomly drawn from the distribution $P(\cdot)$. The new job opportunity triggers a three-player bargaining between the worker, the incumbent and the poaching employer. The mechanism is identical to the one described in Cahuc, Postel-Vinay and Robin (2006), al-

\footnotetext{
${ }^{31}$ An alternative way to state the same assumption is that unskilled workers are only hired conditional on successful bargaining with the skilled worker. When paying the exogenous wage rate $\bar{w}$, unskilled workers can be hired (and dismissed) frictionlessly.
} 
though it is implemented in our much simplified framework. ${ }^{32}$ All parties have perfect information about their types, wage offers are observable and verifiable and there are no renegotiation costs. The sequence of events is the following: once the worker makes contact with a new potential firm, the incumbent and the poaching employer simultaneously make a wage offer, then the worker chooses the best offer and, finally, she goes back to the employer whose offer was refused and renegotiates using the new wage proposal as an outside option.

The outcome of this game depends on the types of the employers. If the poaching firm is more skill-intensive than the incumbent (i.e. $\left.\rho^{\prime}<\rho\right)$, then the latter is drawn to offer the entire surplus to the worker, namely $\left[x_{h}-\rho(\bar{w}-1)\right]$, in an attempt to retain her. ${ }^{33}$ Then, the worker negotiates a new wage with the poaching employer using this as an outside option. Eventually, the worker will move to the new more skill-intensive firm with the following wage:

$$
w\left(\rho, \rho^{\prime}\right)=\left[x_{h}-\rho(\bar{w}-1)\right]+\gamma\left(\rho-\rho^{\prime}\right)(\bar{w}-1) \quad \text { with } \rho^{\prime}<\rho
$$

where we indicate with $w\left(\rho, \rho^{\prime}\right)$ the wage paid by a firm of type $\rho^{\prime}$ to a skilled worker who had the alternative option of working for a $\rho$-firm. Such wage is equal to the full surplus of the alternative match plus a fraction $\gamma$ of the difference between the surpluses of the two potential matches.

Of course, it might also happen that the new potential employer is less skillintensive that the incumbent, i.e. $\rho \leq \rho^{\prime}$. In this case the worker might still have an interest in triggering the renegotiation game because it may allow her to command a higher wage from the incumbent employer. Now it is the poaching firm which is drawn to offer the entire surplus to the worker, who then uses it as an outside option in the negotiation with the current employer to obtain the following wage:

$$
w\left(\rho^{\prime}, \rho\right)=\left[x_{h}-\rho^{\prime}(\bar{w}-1)\right]+\gamma\left(\rho^{\prime}-\rho\right)(\bar{w}-1) \quad \text { with } \rho \leq \rho^{\prime}
$$

Obviously, the worker will engage in the negotiation game only if $w\left(\rho^{\prime}, \rho\right)$ is higher than $w_{0}(\rho)$ and this is guaranteed when $\rho^{\prime}<\frac{X_{H}}{\bar{w}-1}$. This is exactly the same condition required for the total surplus of the match without renegotiation

\footnotetext{
${ }^{32}$ The non-renegotiation wage of equation 8 plays in our setting the same role as the wage negotiated by the unemployed workers in Cahuc, Postel-Vinay and Robin (2006).

${ }^{33} \mathrm{We}$ assume that when the worker is indifferent between the new and the incumbent employer she remains in her current job.
} 
to be positive (see equation 7). In other words, production technologies with $\rho$ larger than $\frac{X_{H}}{\bar{w}-1}$ are not profitable in equilibrium. ${ }^{34}$

To sum up, this simple model is able to rationalize all our empirical findings as follows.

- As the wage of unskilled workers increases, the wages of the skilled decrease and such spillover effect is stronger in less skill-intensive firms (i.e. firms with higher $\rho$ ). This is consistent with our main findings in Table 3 and 5 .

- The spillover effect is stronger for the job stayers, as in Table 5 and in Figure 5. To see this, consider two skilled workers - A and B - who are both employed at the same incumbent firm of type $\rho$. At some point, they both find an alternative employer. However, worker A is lucky and meets a more skill-intensive firm of type $\rho^{\prime}<\rho$ whereas worker B finds a less skill-intensive firm of type $\rho^{\prime \prime}>\rho$. Then, worker A leaves the original employer and joins the new firm at the wage $w\left(\rho, \rho^{\prime}\right)$ while worker B remains in her current job but renegotiates the wage to $w\left(\rho^{\prime \prime}, \rho\right)$. Then, it is easy to show that the derivative with respect to $\bar{w}$ of $w\left(\rho^{\prime \prime}, \rho\right)$, the wage of the job stayer, is more negative than the same derivative of $w\left(\rho, \rho^{\prime}\right)$, the wage of the job mover. ${ }^{35}$

- Skilled workers move from less to more skill-intensive firms with probability $\lambda P(\rho)$. Hence, they are more likely to move when they are employed at less skill-intensive firms. This is consistent with our findings in Table 6 and Figure 6.

- As the wage of unskilled workers increases the less skill-intensive firms exit the market, as shown in Table 7. In fact, we have shown that only firms with $\rho \leq \frac{X_{H}}{\bar{w}-1}$ are associated with non-negative surpluses. As $\bar{w}$ increases, this threshold decreases and firms with unprofitable technologies leave the market.

\footnotetext{
${ }^{34}$ For simplicity we have set the value of unemployment to zero. As a consequence workers always engage in the renegotiation process because their outside option will always increase regardless of the type of the poaching firm.

${ }^{35}$ Note that $\frac{\partial w\left(\rho, \rho^{\prime}\right)}{\partial \bar{w}}=-(1-\gamma) \rho-\gamma \rho^{\prime}<0$ and $\frac{\partial w\left(\rho^{\prime \prime}, \rho\right)}{\partial \bar{w}}=-(1-\gamma) \rho^{\prime \prime}-\gamma \rho<0$. Given that $\rho^{\prime}<\rho<\rho^{\prime \prime}$, it follows that $\frac{\partial w\left(\rho^{\prime \prime}, \rho\right)}{\partial \bar{w}}<\frac{\partial w\left(\rho, \rho^{\prime}\right)}{\partial \bar{w}}$.
} 


\section{Conclusions}

In this paper we study a unique wage indexation mechanism that was adopted in Italy in the late 1970s and early 1980s, the Scala Mobile (SM). Because of the way it was designed, granting absolute wage increases of the same amount for all workers, the SM induced large real pay rises to workers at the bottom of the distribution and it was irrelevant towards the top. Nevertheless, we document that the system generated important spillover effects on high-wage workers who experienced lower wage growth as their low-wage colleagues were given higher mandatory SM adjustments. This effect was stronger for skilled workers employed at establishments with larger shares of unskilled workers, suggesting that the spillover effect was generated by intra-firm bargaining.

We rationalize these results with a theoretical model where the wages of unskilled workers are set exogenously whereas those of the skilled are negotiated. Given the complementarity of skill types in the production process, an increase in the exogenous wage rate of the unskilled induces firms to extract more rents from the jobs of their skilled colleagues. This mechanism is consistent with our empirical evidence and suggests that labor market institutions may have an important role in explaining the evolution of inequality also at the top of the distribution of wages.

This is an important result because the large literature on labor market institutions and inequality has focused almost exclusively on the lower end of the distribution. In fact, many important studies have identified the effect of institutions such as minimum wages and unions using as an identification assumption the hypothesis of no causal effect on high wages. ${ }^{36}$

We also show that part of the adjustment to the SM took place through job turnover. As predicted by our model, high mandatory wage rises to the unskilled induced skilled workers to move towards the most skill-intensive firms and away from the least skill-intensive ones, which were eventually more likely to exit the market.

The SM was abolished in the early 1990s in the aftermath of a profound wave of frustration among skilled white-collars, who felt damaged by the increased levels of wage compression induced by the indexation system. This

\footnotetext{
${ }^{36}$ For example, the famous study by Di Nardo, Fortin and Lemieux (1996) constructs the counterfactual of the lower end of the wage distribution in the absence of the minimum wage with the symmetric of the upper part of the same distribution.
} 
is perfectly in line with our results and intriguingly at odds with much of the literature on inequality aversion (Truman F. Bewley, 1999; Fehr and Schmidt, 1999). Contrary to the predictions of many studies in this area, our findings indicate that under certain circumstances individuals can be averse to too much intra-firm wage equality. We cannot say whether skilled workers left the least skill-intensive firms because they could get higher wages elsewhere or because their wages were getting too close to those of the unskilled. However, we believe that this is a very promising avenue for future research that can be fruitfully pursued exploiting the same SM mechanism of this paper.

\section{References}

Autor, David H., Lawrence F. Katz, and Melissa S. Kearney. 2006. "The Polarization of the U.S. Labor Market." The American Economic Review, 96(2): 189-194.

Bewley, Truman F. 1999. Why wages don't fall during a recession. Harvard University Press.

Cahuc, Pierre, Fabien Postel-Vinay, and Jean-Marc Robin. 2006. "Wage Bargaining with On-the-Job Search: Theory and Evidence." Econometrica, 74(2): pp. 323-364.

Cahuc, Pierre, Francois Marque, and Etienne Wasmer. 2008. "A Theory of Wages and Labor Demand with Intra-Firm Bargaining and Matching Frictions." International Economic Review, 49(3): pp. 943-972.

Card, David, Alexandre Mas, Enrico Moretti, and Emmanuel Saez. 2012. "Inequality at Work: The Effect of Peer Salaries on Job Satisfaction." American Economic Review, 102(6): 2981-3003.

Card, David, Francesco Devicienti, and Agata Maida. 2014. "Rent-sharing, Holdup, and Wages: Evidence from Matched Panel Data." Review of Economic Studies, 81(1): 84-111.

Card, David, W. Craig Riddell, and Thomas Lemieux. 2004. "Unions and Wage Inequality." Journal of Labor Research, 24(4): 519-562. 
Charness, Gary, and Peter Kuhn. 2007. "Does Pay Inequality Affect Worker Effort? Experimental Evidence.” Journal of Labor Economics, 25: 693-723.

Cingano, Federico, and Alfonso Rosolia. 2012. "People I Know: Job Search and Social Networks.” Journal of Labor Economics, 30(2): 291 - 332.

Clark, Andrew E., and Claudia Senik. 2010. "Who Compares to Whom? The Anatomy of Income Comparisons in Europe." Economic Journal, 120(544): 573-594.

Clark, Andrew E., David Masclet, and Marie Claire Villeval. 2010. "Effort and Comparison Income: Experimental and Survey Evidence." Industrial and Labor Relations Review, 63(3): 407-426.

Di Nardo, John, and David S. Lee. 2004. "Economic Impacts of New Unionization On Private Sector Employers: 1984-2001.” The Quarterly Journal of Economics, 119(4): 1383-1441.

Di Nardo, John, Kevin F Hallock, and Jörn-Steffen Pischke. 2000. "Unions And The Labour Market For Managers.” C.E.P.R. Discussion Papers CEPR Discussion Papers 2418.

Di Nardo, John, Nicole Fortin, and Thomas Lemieux. 1996. "Labor market institutions and the distribution of wages, 1973-1992: A semiparametric approach." Econometrica, 64(5): 1001-1044.

Engelmann, Dirk, and Martin Strobel. 2004. "Inequality Aversion, Efficiency, and Maximin Preferences in Simple Distribution Experiments." American Economic Review, 94(4): 857-869.

Erikson, Christopher L., and Andrea Ichino. 1995. "Wage differentials in Italy: Market forces, institutions, and inflation.” In Differences and changes in the wage structure. , ed. University of Chicago Press. Richard B. Freeman and Lawrence F. Katz.

Fehr, Ernst, and Klaus M. Schmidt. 1999. “A Theory Of Fairness, Competition, And Cooperation." The Quarterly Journal of Economics, 114(3): 817868 . 
Gramlich, Edward M. 1976. "Impact of Minimum Wages on Other Wages, Employment, and Family Incomes.” Brookings Papers on Economic Activity, 7(2): 409-462.

Grossman, Jean Baldwin. 1983. "The Impact of the Minimum Wage on Other Wages." The Journal of Human Resources, 18(3): 359-378.

Guiso, Luigi, Luigi Pistaferri, and Fabiano Schivardi. 2005. "Insurance within the Firm.” Journal of Political Economy, 113(5): 1054-1087.

Guiso, Luigi, Luigi Pistaferri, and Fabiano Schivardi. 2013. "Credit within the Firm." Review of Economic Studies, 80(1): 211-247.

Lee, David S. 1999. "Wage Inequality in the United States during the 1980s: Rising Dispersion or Falling Minimum Wage?" The Quarterly Journal of Economics, 114(3): 977-1023.

Leonardi, Marco, and Giovanni Pica. 2013. "Who Pays for it? The Heterogeneous Wage Effects of Employment Protection Legislation.” Economic Journal, 123(12): 1236-1278.

Manacorda, Marco. 2004. "Can the Scala Mobile explain the fall and rise of earnings inequality in Italy? A semiparametric analysis, 1977-1993.” Journal of Labor Economics, 22(3): 585-613.

Mas, Alexandre. 2006. "Pay, Reference Points, and Police Performance." The Quarterly Journal of Economics, 121(3): 783-821.

Rabin, Matthew. 2006. "A Model of Reference-Dependent Preferences." The Quarterly Journal of Economics, 121(4): 1133-1165.

Rubinstein, Ariel. 1982. "Perfect Equilibrium in a Bargaining Model." Econometrica, 50(1): 97-109.

Stole, Lars A., and Jeffrey Zwiebel. 1996. "Intra-Firm Bargaining under NonBinding Contracts.” The Review of Economic Studies, 63(3): pp. 375-410. 


\section{Figures and Tables}

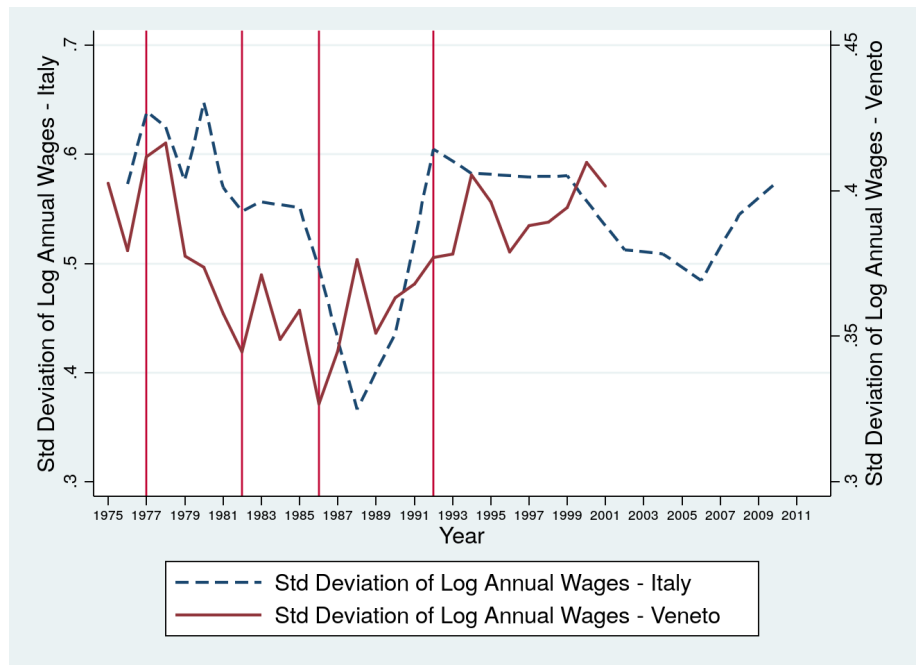

Figure 1: Wage inequality 1975-2011 - Italy and Veneto.

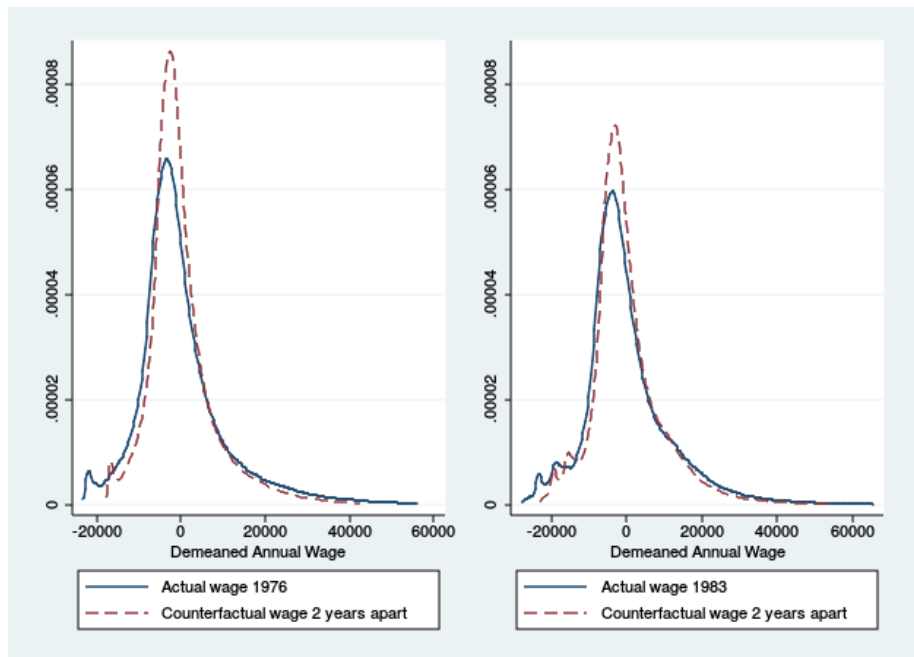

Figure 2: Actual wages and counterfactual distributions due to SM indexation 


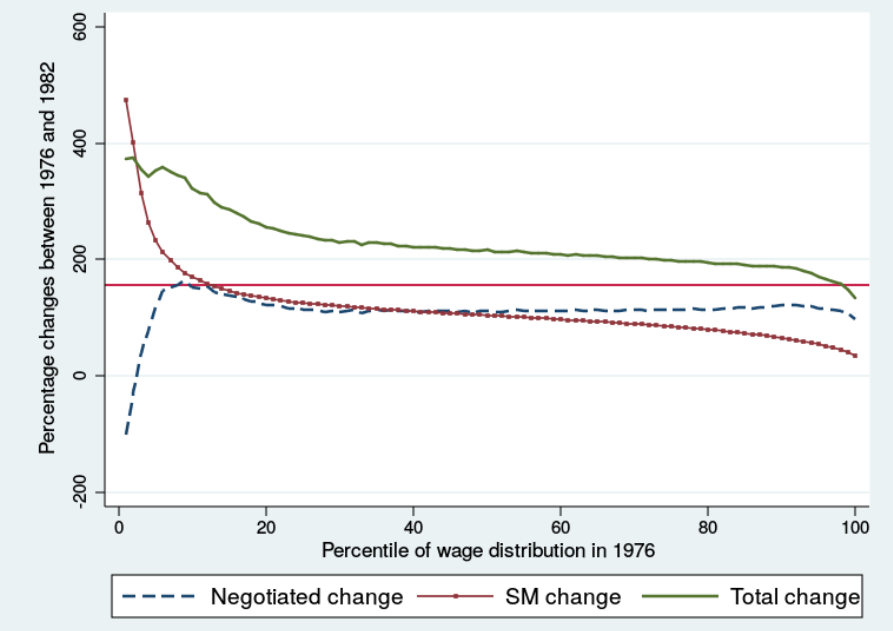

Figure 3: Wage changes in the period 1976-1982 (job stayers only)

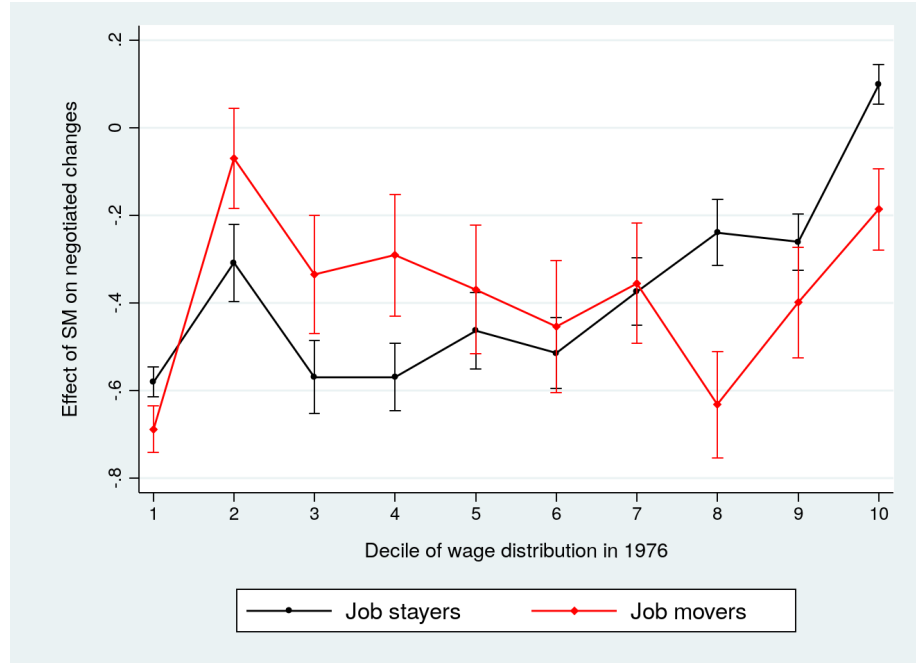

Figure 4: Effect of SM changes on negotiated changes along the wage distribution. 


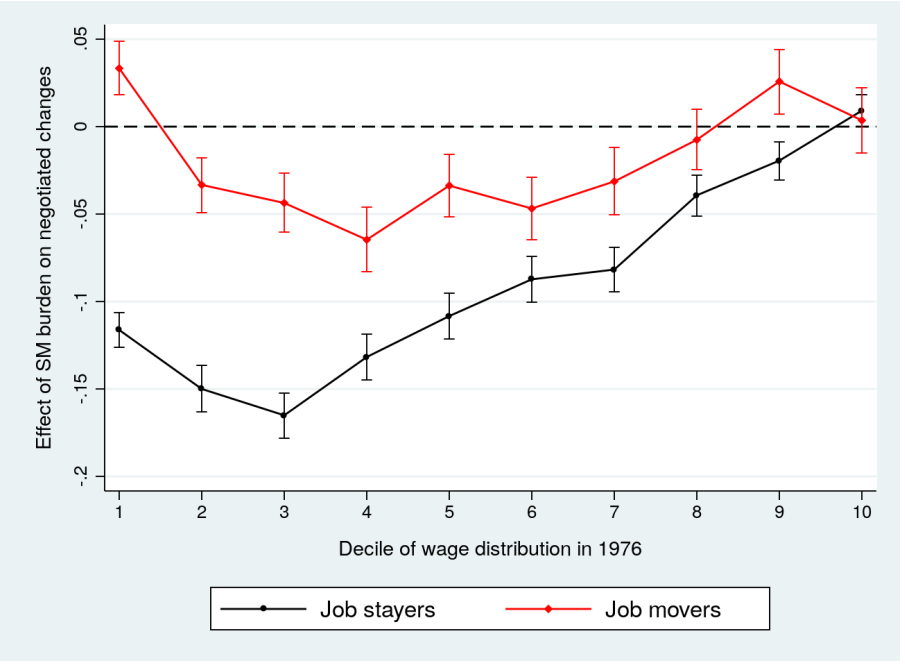

Figure 5: Effect of SM burden on negotiated changes along the wage distribution.
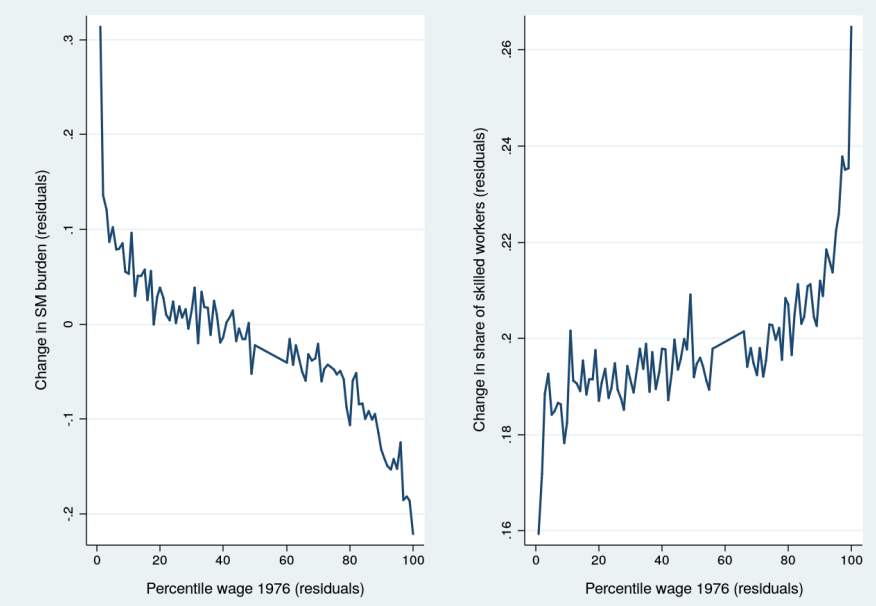

Figure 6: Changes in firm characteristics for job changers. 
Table 1: Descriptive statistics

\begin{tabular}{lcc}
\hline \hline & $\begin{array}{c}\text { Universe of } \\
\text { observations }\end{array}$ & $\begin{array}{c}\text { Estimation } \\
\text { sample }\end{array}$ \\
\cline { 2 - 3 } & $\begin{array}{c}\text { Mean } \\
\text { (Std. Dev.) }\end{array}$ & $\begin{array}{c}\text { Mean } \\
\text { (Std. Dev.) }\end{array}$ \\
\hline Worker-level descriptive statistics & & \\
Female & 0.318 & 0.243 \\
Age & 32.573 & 32.690 \\
& $(12.668)$ & $(10.039)$ \\
White collar & 0.198 & 0.172 \\
Job stayer & \\
Wage in 1976 & \\
& 0.582 & 0.636 \\
Number of workers & 13,214 & 18,217 \\
& $(45,846)$ & $(6,449)$ \\
Firm-level descriptive statistics & $1,103,231$ & 455,324 \\
Number of full-time employees & & \\
& & \\
More than 15 employees & 5.795 & 14.696 \\
Share of white collars & $(50.317)$ & $(82.221)$ \\
Number of firms & 0.053 & 0.153 \\
\hline \hline
\end{tabular}

${ }^{a}$ Job stayers are workers who remain with the sample employer throughout the period 1977-1982.

${ }^{b}$ Wages are reported in Euros at 2014 prices.

All values calculated in the year 1976.

Source: INPS Social Security Archives, 1976-1982. 
Table 2: The functioning of the Scala Mobile - 1977-1982

\begin{tabular}{|c|c|c|c|c|c|}
\hline Year & Month & $\begin{array}{l}P_{t}^{a} \\
{[1]} \\
\end{array}$ & $\begin{array}{l}\Delta P_{t} \\
{[2]} \\
\end{array}$ & $\begin{array}{c}\text { Contingenza } \\
\text { point } \\
{[3]} \\
\end{array}$ & $\begin{array}{c}\text { SM } \\
\text { adjustment } \\
{[2] \times[3]} \\
\end{array}$ \\
\hline 1977 & 1 & 143 & 9 & - & - \\
\hline 1977 & 4 & 149 & 6 & 2,389 & 14,334 \\
\hline 1977 & 7 & 154 & 5 & 2,389 & 11,945 \\
\hline 1977 & 10 & 158 & 4 & 2,389 & 9,556 \\
\hline 1978 & 1 & 162 & 4 & 2,389 & 9,556 \\
\hline 1978 & 4 & 167 & 5 & 2,389 & 11,945 \\
\hline 1978 & 7 & 173 & 6 & 2,389 & 14,334 \\
\hline 1978 & 10 & 178 & 5 & 2,389 & 11,945 \\
\hline 1979 & 1 & 184 & 6 & 2,389 & 14,334 \\
\hline 1979 & 4 & 192 & 8 & 2,389 & 19,112 \\
\hline 1979 & 7 & 198 & 6 & 2,389 & 14,334 \\
\hline 1979 & 10 & 206 & 8 & 2,389 & 19,112 \\
\hline 1980 & 1 & 214 & 8 & 2,389 & 19,112 \\
\hline 1980 & 4 & 226 & 12 & 2,389 & 28,668 \\
\hline 1980 & 7 & 234 & 8 & 2,389 & 19,112 \\
\hline 1980 & 10 & 244 & 10 & 2,389 & 23,890 \\
\hline 1981 & 1 & 255 & 11 & 2,389 & 26,279 \\
\hline 1981 & 4 & 269 & 14 & 2,389 & 33,446 \\
\hline 1981 & 7 & 279 & 10 & 2,389 & 23,890 \\
\hline 1981 & 10 & 288 & 9 & 2,389 & 21,501 \\
\hline 1982 & 1 & 297 & 9 & 2,389 & 21,501 \\
\hline 1982 & 4 & 309 & 12 & 2,389 & 28,668 \\
\hline 1982 & 7 & 322 & 13 & 2,389 & 31,057 \\
\hline 1982 & 10 & 335 & 13 & 2,389 & 31,057 \\
\hline
\end{tabular}


Table 3: Negotiated wage changes and the SM

\begin{tabular}{|c|c|c|c|}
\hline Dependent var. $=\Delta w_{i}^{n}$ & $\overline{(1)}$ & (2) & (3) \\
\hline$\Delta w_{i}^{s}$ & $\begin{array}{c}-0.318 * * * \\
(0.007)\end{array}$ & $\begin{array}{c}-0.248 * * * \\
(0.007)\end{array}$ & - \\
\hline$[1=\text { job stayer }]^{a}$ & - & $\begin{array}{c}0.004 * * * \\
(0.001)\end{array}$ & - \\
\hline$\Delta w_{i}^{s} \times[1=\text { job stayer }]^{a}$ & - & $\begin{array}{c}-0.104 * * * \\
(0.005)\end{array}$ & - \\
\hline$\Delta w_{i}^{s} \times$ wage decile $1^{b}$ & - & - & $\begin{array}{c}-0.763 * * * \\
(0.009)\end{array}$ \\
\hline$\Delta w_{i}^{s} \times$ wage decile $2^{b}$ & - & - & $\begin{array}{c}-0.942 * * * \\
(0.013)\end{array}$ \\
\hline$\Delta w_{i}^{s} \times$ wage decile $3^{b}$ & - & - & $\begin{array}{c}-1.037 * * * \\
(0.014)\end{array}$ \\
\hline$\Delta w_{i}^{s} \times$ wage decile $4^{b}$ & - & - & $\begin{array}{c}-0.962 * * * \\
(0.015)\end{array}$ \\
\hline$\Delta w_{i}^{s} \times$ wage decile $5^{b}$ & - & - & $\begin{array}{c}-0.847 * * * \\
(0.017)\end{array}$ \\
\hline$\Delta w_{i}^{s} \times$ wage decile $6^{b}$ & - & - & $\begin{array}{c}-0.718 * * * \\
(0.018)\end{array}$ \\
\hline$\Delta w_{i}^{s} \times$ wage decile $7^{b}$ & - & - & $\begin{array}{c}-0.591 * * * \\
(0.019)\end{array}$ \\
\hline$\Delta w_{i}^{s} \times$ wage decile $8^{b}$ & - & - & $\begin{array}{c}-0.471 * * * \\
(0.019)\end{array}$ \\
\hline$\Delta w_{i}^{s} \times$ wage decile $9^{b}$ & - & - & $\begin{array}{c}-0.351 * * * \\
(0.020)\end{array}$ \\
\hline$\Delta w_{i}^{s} \times$ wage decile $10^{b}$ & - & - & $\begin{array}{c}-0.349 * * * \\
(0.023)\end{array}$ \\
\hline Number of Observations & 455,324 & 455,324 & 455,324 \\
\hline \multicolumn{4}{|c|}{$\begin{array}{l}{ }^{a} \text { Workers who are employed in the same firm throughout the period } \\
1976-1982 . \\
{ }^{b} \text { Decile of the distribution of wages in } 1976 \text {. } \\
\Delta w_{i}^{s} \text { is the negotiated percentage change in real wages over the period } \\
1976-1982 . \Delta w_{i}^{s} \text { percentage change in real wages commanded by the SM } \\
\text { from } 1976 \text { to } 1982 \text {. } \\
\text { All specifications include a quadratic function of the wage percentile in } \\
\text { 1976, age, age squared, a gender dummy and fixed effects for the firms } \\
\text { where the worker was employed in } 1976 . \\
\text { Standard errors in parentheses. } * p<0.10, * * p<0.05, * * * p<0.01\end{array}$} \\
\hline
\end{tabular}


Table 4: SM burden and firm's employment

\begin{tabular}{|c|c|c|c|c|}
\hline Quantiles $^{a}$ of & Average & Share of & \multicolumn{2}{|c|}{ Share of workers by wage quintilec } \\
\hline SMburden $_{i j}$ & SMburden $_{i j}$ & white collars ${ }^{b}$ & bottom & top \\
\hline 1 & -0.059 & 0.293 & 0.016 & 0.498 \\
\hline 2 & -0.032 & 0.156 & 0.036 & 0.073 \\
\hline 3 & -0.017 & 0.111 & 0.076 & 0.019 \\
\hline 4 & 0.000 & 0.079 & 0.262 & 0.006 \\
\hline 5 & 0.053 & 0.102 & 0.762 & 0.002 \\
\hline Total & -0.011 & 0.148 & 0.230 & 0.120 \\
\hline
\end{tabular}

${ }^{a}$ Quintiles of the distribution of SMburden $_{i j}$ across firms.

${ }^{b}$ In the firm's total employment in 1976.

${ }^{c}$ Distribution of individual wages in 1976.

All statistics are computed over the sample of $(47,682)$ firms observed in 1976. 
Table 5: Negotiated wage changes and the SM within the firm

\begin{tabular}{|c|c|c|c|}
\hline Dependent var. $=\Delta w_{i}^{n}$ & $(1)$ & $(2)$ & (3) \\
\hline SMburden $_{i j}$ & $\begin{array}{c}-0.075^{* * *} \\
(0.001)\end{array}$ & $\begin{array}{c}-0.009^{* * * *} \\
(0.002)\end{array}$ & - \\
\hline$\Delta w_{i}^{s}$ & $\begin{array}{c}-0.542 * * * \\
(0.005)\end{array}$ & $\begin{array}{c}-0.476 * * * \\
(0.005)\end{array}$ & - \\
\hline$[1=\text { job stayer }]^{a}$ & - & $\begin{array}{c}-0.075^{* * * *} \\
(0.002)\end{array}$ & - \\
\hline SMburden $_{i j} \times[1=\text { job stayer }]^{a}$ & - & $\begin{array}{c}-0.107 * * * \\
(0.002)\end{array}$ & - \\
\hline SMburden $_{i j} \times$ wage decile $1^{b}$ & - & - & $\begin{array}{c}-0.060 * * * \\
(0.002)\end{array}$ \\
\hline SMburden $_{i j} \times$ wage decile $2^{b}$ & - & - & $\begin{array}{c}-0.067 * * * \\
(0.004)\end{array}$ \\
\hline SMburden $_{i j} \times$ wage decile $3^{b}$ & - & - & $\begin{array}{c}-0.092 * * * \\
(0.005)\end{array}$ \\
\hline SMburden $_{i j} \times$ wage decile $4^{b}$ & - & - & $\begin{array}{c}-0.093 * * * \\
(0.006)\end{array}$ \\
\hline SMburden $_{i j} \times$ wage decile $5^{b}$ & - & - & $\begin{array}{c}-0.073 * * * \\
(0.006)\end{array}$ \\
\hline SMburden $_{i j} \times$ wage decile $6^{b}$ & - & - & $\begin{array}{c}-0.075 * * * \\
(0.006)\end{array}$ \\
\hline SMburden $_{i j} \times$ wage decile $7^{b}$ & - & - & $\begin{array}{c}-0.073 * * * \\
(0.006)\end{array}$ \\
\hline SMburden $_{i j} \times$ wage decile $8^{b}$ & - & - & $\begin{array}{c}-0.042 * * * \\
(0.006)\end{array}$ \\
\hline SMburden $_{i j} \times$ wage decile $9^{b}$ & - & - & $\begin{array}{c}-0.020 * * * \\
(0.005)\end{array}$ \\
\hline SMburden $_{i j} \times$ wage decile $10^{b}$ & - & - & $\begin{array}{c}0.057 * * * \\
(0.005)\end{array}$ \\
\hline Number of Observations & 455,324 & 455,324 & 455,324 \\
\hline
\end{tabular}

${ }^{a}$ Workers who are employed in the same firm throughout the period 1976-1982.

${ }^{b}$ Decile of the distribution of wages in 1976.

$\Delta w_{i}^{s}$ is the negotiated percentage change in real wages over the period 1976-1982. $\Delta w_{i}^{s}$ percentage change in real wages commanded by the SM from 1976 to 1982. SMburden $_{i j}$ is sum of all real SM adjustments due by firm the firm in 1977 over the firm's wage bill in 1976 (see Section 4.1 for details). This variable is standardized between 0 and 1 for simplicity of interpretation. All specifications include a constant, a quadratic function of the wage percentile in 1976, age, age squared and a gender dummy. The specification in column (3) also includes the interactions of $\Delta w_{i}^{s}$ and the wage deciles.

Standard errors in parentheses. $* p<0.10, * * p<0.05$, *** $p<0.01$ 
Table 6: Probability of changing employer

\begin{tabular}{|c|c|c|}
\hline $\bar{D}$ ependent var.= prob. of job changing ${ }^{a}$ & $(1)$ & $\overline{(2)}$ \\
\hline \multirow[t]{2}{*}{ SMburden $_{i j}$} & $0.031 * * *$ & - \\
\hline & $(0.001)$ & - \\
\hline \multirow[t]{2}{*}{$\Delta w_{i}^{s}$} & $-0.135 * * *$ & $-0.053 * * *$ \\
\hline & $(0.004)$ & $(0.005)$ \\
\hline \multirow[t]{2}{*}{ SMburden $_{i j} \times$ wage decile $1^{b}$} & - & $-0.024 * * *$ \\
\hline & & $(0.002)$ \\
\hline \multirow[t]{2}{*}{ SMburden $_{i j} \times$ wage decile $2^{b}$} & - & $0.033 * * *$ \\
\hline & & $(0.003)$ \\
\hline \multirow[t]{2}{*}{ SMburden $_{i j} \times$ wage decile $3^{b}$} & - & -0.005 \\
\hline & & $(0.003)$ \\
\hline \multirow[t]{2}{*}{ SMburden $_{i j} \times$ wage decile $4^{b}$} & - & $0.021 * * *$ \\
\hline & & $(0.004)$ \\
\hline \multirow[t]{2}{*}{ SMburden $_{i j} \times$ wage decile $5^{b}$} & - & $0.040 * * *$ \\
\hline & & $(0.005)$ \\
\hline \multirow[t]{2}{*}{ SMburden $_{i j} \times$ wage decile $6^{b}$} & - & $0.050 * * *$ \\
\hline & & $(0.005)$ \\
\hline \multirow[t]{2}{*}{ SMburden $_{i j} \times$ wage decile $7^{b}$} & - & $0.076 * * *$ \\
\hline & & $(0.005)$ \\
\hline \multirow[t]{2}{*}{ SMburden $_{i j} \times$ wage decile $8^{b}$} & - & $0.074 * * *$ \\
\hline & & $(0.004)$ \\
\hline \multirow[t]{2}{*}{ SMburden $_{i j} \times$ wage decile $9^{b}$} & - & $0.106 * * *$ \\
\hline & & $(0.003)$ \\
\hline \multirow[t]{2}{*}{ SMburden $_{i j} \times$ wage decile $10^{b}$} & - & $0.195 * * *$ \\
\hline & & $(0.003)$ \\
\hline Number of Observations & 455,324 & 455,324 \\
\hline
\end{tabular}

${ }^{a}$ The dependent variable is a dummy equal to one for workers who changed employer at least once at some point between 1976 and 1982.

${ }^{b}$ Decile of the distribution of wages in 1976.

$\Delta w_{i}^{s}$ is the negotiated percentage change in real wages over the period 1976-1982. $\Delta w_{i}^{s}$ percentage change in real wages commanded by the SM from 1976 to 1982. SMburden $i j$ is sum of all real SM adjustments due by firm the firm in 1977 over the firm's wage bill in 1976 (see Section 4.1 for details). This variable is standardized between 0 and 1 for simplicity of interpretation.

All specifications include a quadratic function of the wage percentile in 1976, age, age squared, a gender dummy and fixed effects for the firms where the worker was employed in 1976.

Standard errors in parentheses. $* p<0.10$, ** $p<0.05$, *** $p<0.01$ 
Table 7: Probability of firm exit

\begin{tabular}{|c|c|c|c|}
\hline Dependent var.= prob. of firm exit ${ }^{a}$ & (1) & $(2)$ & (3) \\
\hline \multirow[t]{2}{*}{ Firm share of white collar employees } & $-0.092 * * *$ & - & - \\
\hline & $(0.008)$ & - & - \\
\hline \multirow[t]{2}{*}{ Firm SM burden } & - & $0.011 * * *$ & - \\
\hline & - & $(0.002)$ & - \\
\hline \multirow[t]{2}{*}{ Firm SM burden decile $1^{b}$} & - & - & $0.243 * * *$ \\
\hline & - & - & $(0.007)$ \\
\hline \multirow[t]{2}{*}{ Firm SM burden decile $2^{b}$} & - & - & $0.268 * * *$ \\
\hline & - & - & $(0.007)$ \\
\hline \multirow[t]{2}{*}{ Firm SM burden decile $3^{b}$} & - & - & $0.284 * * *$ \\
\hline & - & - & $(0.007)$ \\
\hline \multirow[t]{2}{*}{ Firm SM burden decile $4^{b}$} & - & - & $0.274 * * *$ \\
\hline & - & - & $(0.007)$ \\
\hline \multirow{2}{*}{ Firm SM burden decile $5^{b}$} & - & - & $0.274 * * *$ \\
\hline & - & - & $(0.007)$ \\
\hline \multirow[t]{2}{*}{ Firm SM burden decile $6^{b}$} & - & - & $0.286^{* * *}$ \\
\hline & - & - & $(0.007)$ \\
\hline \multirow[t]{2}{*}{ Firm SM burden decile $7^{b}$} & - & - & $0.287 * * *$ \\
\hline & - & - & $(0.007)$ \\
\hline \multirow[t]{2}{*}{ Firm SM burden decile $8^{b}$} & - & - & $0.288 * * *$ \\
\hline & - & - & $(0.007)$ \\
\hline \multirow[t]{2}{*}{ Firm SM burden decile $9^{b}$} & - & - & $0.310 * * *$ \\
\hline & - & - & $(0.007)$ \\
\hline \multirow[t]{2}{*}{ Firm SM burden decile $10^{b}$} & - & - & $0.307 * * *$ \\
\hline & - & - & $(0.007)$ \\
\hline \multirow[t]{2}{*}{ Constant } & $0.296 * * *$ & $0.277 * * *$ & - \\
\hline & $(0.002)$ & $(0.002)$ & - \\
\hline
\end{tabular}

\footnotetext{
Number of Observations

47,682

47,682

47,682

${ }^{a}$ The dependent variable is a dummy equal to one for firms which ceased operating at some point between 1976 and 1982 .

${ }^{b}$ Decile of the distribution of SM burden in 1976. This variable is standardized between 0 and 1 for simplicity of interpretation.

SM burden is sum of all real SM adjustments due by firm the firm in 1977 over the firm's wage bill in 1976 (see Section 4.1 for details).

Standard errors in parentheses. $* p<0.10, * * p<0.05, * * * p<0.01$
} 